\title{
Influence of Polyphosphoric Acid on the Consistency and Composition of Formulated Bitumen: Standard Characterization and NMR Insights
}

\author{
Catarina Varanda, ${ }^{1,2}$ Inês Portugal, ${ }^{1}$ Jorge Ribeiro, ${ }^{2}$ Artur M. S. Silva, ${ }^{3}$ and Carlos M. Silva ${ }^{1}$ \\ ${ }^{1}$ Department of Chemistry, CICECO-Aveiro Institute of Materials, University of Aveiro, 3810-193 Aveiro, Portugal \\ ${ }^{2}$ Galp Energia, Refinaria de Matosinhos, Rua Belchior Robles, 4450-802 Leça da Palmeira, Portugal \\ ${ }^{3}$ Department of Chemistry, QOPNA, University of Aveiro, 3810-193 Aveiro, Portugal \\ Correspondence should be addressed to Inês Portugal; inesport@ua.pt and Carlos M. Silva; carlos.manuel@ua.pt
}

Received 11 April 2016; Revised 28 June 2016; Accepted 29 June 2016

Academic Editor: Adam Voelkel

Copyright ( 2016 Catarina Varanda et al. This is an open access article distributed under the Creative Commons Attribution License, which permits unrestricted use, distribution, and reproduction in any medium, provided the original work is properly cited.

Over the recent years, bitumen modification with polymers, acids, or mineral fillers has gained relevance to adjust its performance properties. This work reports the use of polyphosphoric acid (PPA) for the modification of formulated bitumen. With this objective, an in-depth literature review on PPA modification was firstly performed. Subsequently, five individual refinery components were selected for the preparation of bitumen blends, namely, asphaltic residue, vacuum residue, and three lube oils extracts. Seven binary/ternary bitumen blends were prepared and then treated with PPA. Afterwards, the five components and the unmodified and PPA-modified bitumen were characterized by standard methods (penetration, softening point, and penetration index), SARA analysis, elemental analysis, and ${ }^{31} \mathrm{P}$ and ${ }^{1} \mathrm{H}$ nuclear magnetic resonance (NMR) spectroscopy. The results evidenced higher asphaltenes and lower saturates/resins contents in PPA-modified bitumen. The NMR data suggest that the paraffinic chains became longer, the content of condensed aromatics increased, more substituted aromatic structures appeared, and $\alpha$-hydrogen in aromatic structures diminished. These findings disclosed the improved consistency and oxidation stability of PPA-modified bitumen blends.

\section{Introduction}

The European Committee for Standardization defines bitumen as a virtually nonvolatile, adhesive, and waterproofing dark brown viscous organic material derived from crude oil or present in natural asphalt [1]. Due to its binding and hydrophobic properties, bitumen is commonly used for the construction of pavements and waterproof systems $[2,3]$. Bitumen properties are related to its composition, which in turn depends strongly on the type and origin of the crude oil. However, the precise identification of the molecular composition and structure of bitumen is almost impossible; therefore, they are often characterized by fractionation techniques $[3,4]$. For instance, the SARA method is based on sequential chromatographic separation of bitumen components into four generic groups according to their polarity and solubility, namely, saturates (S), aromatics (A), resins $(\mathrm{R})$, and asphaltenes (A) $[3,5,6]$. Commonly, the saturates fraction contains linear and branched alkanes eluted with a paraffinic solvent (e.g., $n$-hexane), the aromatics fraction is constituted mainly by alkylated C5 and C6 cyclic structures eluted with a moderately polar solvent (e.g., toluene), the resins are alkylated and cycloalkylated structures with 23 aromatic rings (e.g., eluted with tetrahydrofuran), and asphaltenes are heavier aromatic polycyclic structures [3]. Moreover, bitumen contains heteroatoms (such as sulfur, oxygen, and nitrogen) normally embedded in the molecular structure of the aromatic rings $[4,7]$. 
The structure of bitumen is controversial but the colloidal model, proposed by Rosinger [8] though generally attributed to Nellensteyn [9], still prevails, especially for explaining the interactions between modifiers and bitumen fractions $[6,10]$. According to this model, bitumen is considered as a suspension of asphaltene micelles peptized by resins, dispersed in an oily medium constituted by saturates and aromatics [3, 10-12]. Depending on the relative contents of these fractions, bitumen exhibits different rheological properties used for its classification into three distinct types, specifically: "sol" (viscous) bitumen which has a colloidal structure constituted by noninteracting micelles and behaves as Newtonian fluid; "gel" (elastic) bitumen which is characterized by a three-dimensional colloidal structure and high resilience; and "sol-gel" (viscoelastic) bitumen which exhibits an intermediate behavior with elastic effects in the initial stages of deformation and a colloidal structure characterized by the presence of supermicelles $[13,14]$.

Over the recent years, bitumen has become a highly technical material with modifiers (e.g., polymers, acids, and mineral fillers) gaining relevance in the control of the performance properties of modified bitumen $[3,15]$. Polyphosphoric acid (PPA) is an example of a reactive modifier that can be used by itself or in conjugation with a suitable polymer, in this case, with considerable economic benefits [16]. In general, the concentrations of PPA in bitumen are in the range from 0.2 to $1.2 \mathrm{wt} . \%$ [7] with an optimum at $1.0 \mathrm{wt} . \%$ [17]. Typically, commercial PPA is a mixture of phosphoric acid $\left(\mathrm{H}_{3} \mathrm{PO}_{4}\right)$, pyrophosphoric acid $\left(\mathrm{H}_{4} \mathrm{P}_{2} \mathrm{O}_{7}\right)$, triphosphoric acid $\left(\mathrm{H}_{5} \mathrm{P}_{3} \mathrm{O}_{10}\right)$, and higher oligomers [18].

Bitumen refined from a specific crude oil has characteristic properties related to its consistency, namely, softening point and penetration value at $25^{\circ} \mathrm{C}$ (expressed in $\mathrm{dmm}$ ) which is the base for the European grading system [19]. These properties can be shifted up or down in the refining process or by posterior blending with different grade bitumen or an additive (e.g., a polymer, PPA, or a combination of both) [20]. Bitumen modification with a polymer or with PPA stiffens the product at higher temperatures, improving the resistance to permanent deformation, without negative effects at low temperatures (i.e., between -30 and $\left.5^{\circ} \mathrm{C}\right)$ [18]. It is noteworthy that PPA has been reported to improve the behavior of modified bitumen also at low temperature $\left(\leq 5^{\circ} \mathrm{C}\right)[21]$ and to impart antioxidant properties [18].

In this work, a detailed review of issued patents and scientific literature on the performance of straight-run bitumen (i.e., obtained directly from crude oil distillation) modified with PPA has been accomplished and is presented in the Appendix. On the other hand, since the influence of PPA on formulated bitumen is not reported in the scientific literature, this is the main focus of this paper. It has been studied using phosphorous $\left({ }^{31} \mathrm{P}\right)$ and proton $\left({ }^{1} \mathrm{H}\right)$ nuclear magnetic resonance spectroscopy to evaluate structural modifications, SARA and elemental analyses to evaluate chemical transformations, and standard grading tests (softening point, penetration value, and penetration index) for performance evaluation.

\section{Bitumen Modification with PPA and Its Characterization}

The interaction of PPA with bitumen model compounds was studied by several authors, as summarized in the Appendix. From these studies, it became clear that PPA modification follows different mechanisms depending on the chemical composition of bitumen which is strongly related to the crude oil geographical source. Overall, the reactivity of PPA increases with the polarity of the asphaltene fraction because it enhances PPA dissociation (into $\mathrm{PPA}^{-}$and $\mathrm{H}^{+}$) [3] disrupting the hydrogen bond network formed within the agglomerates of asphaltene micelles. Consequently, the molecular weight of the asphaltene fraction is lowered and the distribution of asphaltenes in the remaining fractions (i.e., saturates, aromatics, and resins, usually called maltene phase) is improved, shifting the bitumen towards a more elastic gel-type structure, as represented schematically in Figure 1 $[13,17]$.

There is a direct relationship between the chemical composition and colloidal structure of bitumen and its performance [13]. Therefore, bitumen is often characterized by related parameters, such as the index of colloidal instability (defined as the ratio of the sum of asphaltenes and saturates to the sum of aromatics and resins), the colloidal indices Ip (i.e., resins-to-asphaltenes ratio) and Is (i.e., ratio of asphaltenes to maltenes), the penetration index (PI), and other rheological measurements.

Several rheological studies of PPA-modified bitumen focused on its performance and stability. For instance, Giavarini et al. [13] reported that PPA-modified bitumen exhibits higher penetration index (PI) and thus improved thermal susceptibility in comparison to unmodified bitumen. Giavarini et al. [16] and Bonemazzi and Giavarini [14] performed rheological studies with polymer-modified bitumen and proved that PPA changes the bitumen structure towards gel type, thus improving the stabilization interactions between the polymer and the bitumen components. Edwards et al. [22] performed rheological tests at low temperature $\left(-25^{\circ} \mathrm{C}\right)$ and established that bitumen modification is influenced by the amount and type (grade) of PPA used and also by the composition of bitumen. Baldino et al. [21] validated the capacity of PPA to decrease the glass transition temperature ( Tg) and to increase the stiffness of modified bitumen.

Another approach is to use spectroscopic techniques to detect specific functional groups in highly complex hydrocarbon mixtures such as bitumen [23-26]. In particular, solution-state ${ }^{1} \mathrm{H}$ and ${ }^{13} \mathrm{C}$ nuclear magnetic resonance (NMR) spectroscopy can be used to identify and quantify the aromatic and aliphatic moieties. This is of utmost importance to understand the molecular interactions between the SARA fractions of bitumen and to explain the influence of modifiers on bitumen performance [27]. For instance, Michon et al. [28, 29] used quantitative ${ }^{13} \mathrm{C}$ NMR data coupled with molecular weight distribution data to estimate structural parameters of bitumen such as, for example, aromaticity and the average number of naphthenic and aromatic rings per molecule. Their final purpose was to define a bitumen "fingerprint" [28], particularly for the aromatic part, in order to propose 


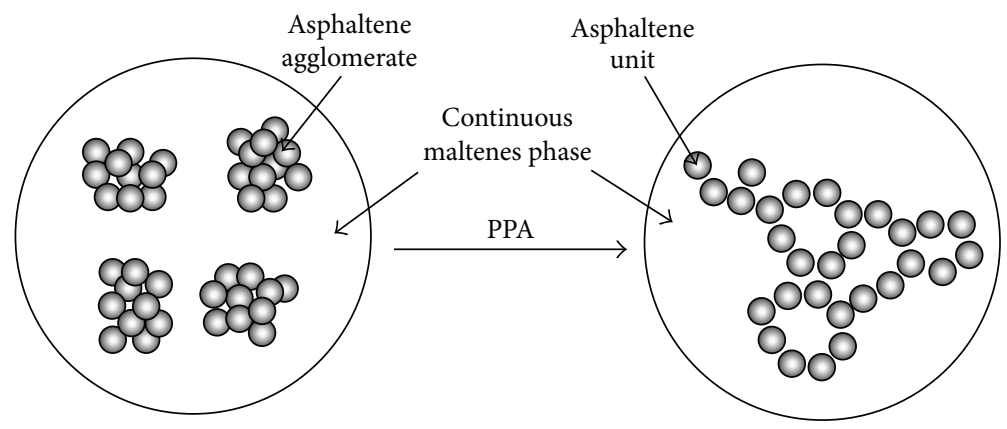

FIGURE 1: Influence of PPA on the colloidal structure of bitumen (adapted from [17]).

TABLE 1: Composition (wt.\%) of the bitumen formulations.

\begin{tabular}{lccccc}
\hline Blend & \multicolumn{5}{c}{ Component } \\
& AR & VR & SN1 & SN2 & SN3 \\
\hline Bit1 & 84.80 & & 15.20 & & \\
Bit2 & 78.44 & & & 21.56 & \\
Bit3 & 78.39 & & & & 21.61 \\
Bit4 & 77.31 & 9.99 & 12.70 & & \\
Bit5 & 70.69 & 10.02 & & 19.29 & \\
Bit6 & 72.27 & 10.06 & & & 17.67 \\
Bit7 & 30.00 & 70.00 & & & \\
\hline
\end{tabular}

a mechanism for bitumen oxidation [29]. The chemical transformations associated with bitumen ageing were investigated by Siddiqui and Ali [30] and Siddiqui [31] using ${ }^{1} \mathrm{H}$ and ${ }^{13} \mathrm{C}$ NMR. Curiously, Molina et al. [23] developed a very fast and reliable method that correlates the area of ${ }^{1} \mathrm{H}$ NMR signals of petroleum residues to their SARA fractions and to some physicochemical properties (e.g., density and S, $\mathrm{N}$, and wax content). Gentile et al. [32] related different ${ }^{1} \mathrm{H}$ NMR spin-spin relaxation times (evaluated by inverse Laplace transform) to different macroaggregates in PPAmodified bitumen. Moreover, bitumen modification with PPA can be analyzed by ${ }^{31} \mathrm{P}$ NMR, a powerful tool to evaluate the structure of phosphorus-containing compounds.

\section{Experimental Procedures}

3.1. Preparation of Bitumen Blends Modified with PPA. The bitumen blends (penetration grade 70/100) used in this work contained asphaltic residue (AR), vacuum residue (VR), and aromatic extracts $\mathrm{SN} 1, \mathrm{SN} 2$, or $\mathrm{SN} 3$, in the proportions presented in Table 1 . These bitumen blends were provided by a Portuguese refinery.

Bitumen modification with PPA was performed in a glass reactor, equipped with a mechanical stirrer and a temperature controller. Bitumen blends $(1000 \pm 0.01 \mathrm{~g})$ were heated to approximately $135^{\circ} \mathrm{C}$ and then PPA grade 105\% (supplied by Innophos, Cranbury, USA) $(8.00 \pm 0.01 \mathrm{~g})$ was added, which corresponds to $0.8 \mathrm{wt}$. $\%$. The mixture was allowed to react for 30 minutes at $135^{\circ} \mathrm{C}$ with constant stirring (ca. $245 \mathrm{rpm}$ ).
3.2. Characterization of Bitumen Components and Blends. The SARA fractions of the individual components and the seven bitumen blends ( Bit $\left._{j}, j=1-7\right)$ were analyzed according to the International Standard method IP-469 using Iatroscan MK-6 TLC-FID instrument (Iatron Laboratories Inc.) [33]. Data acquisition was performed with the DataApex Clarity Lite software, version 3 . Each sample was analyzed in triplicate and the results (peak areas) were averaged and considered as the weight percentage of the corresponding SARA fractions.

Elemental analysis of carbon, hydrogen, and nitrogen in bitumen samples was performed in a Leco TruSpec ${ }^{\circledR}$ instrument (628 Series) following the standard procedure ASTM D5291 [34]. Sulfur content was determined by energydispersive X-ray fluorescence (EDXRF) in Oxford Instruments Lab-X3500, following the International Standard method IP 336 [35]. The analyses were performed using three replicated samples.

For NMR analysis, the bitumen samples $(0.20 \pm 0.01 \mathrm{~g})$ were dissolved in deuteriochloroform $\left(\mathrm{CDCl}_{3}\right.$, SigmaAldrich, 99.8 atom\% D) (1 mL) and analyzed in triplicate. Solution-state ${ }^{1} \mathrm{H}$ NMR measurements were obtained in a Bruker Avance 300 spectrometer (operating at $300.13 \mathrm{MHz}$ ) under the following conditions: spectral window of $6887 \mathrm{~Hz}$, with a $30^{\circ}$ pulse width $(3.63 \mu \mathrm{s})$, acquisition time $2.4 \mathrm{~s}$, relaxation delay $1 \mathrm{~s}, 32768$ data points, and 128 scans. Solution-state ${ }^{31} \mathrm{P}$ NMR spectra were acquired at room temperature in a Bruker Avance 300 spectrometer at a nominal frequency of $121.5 \mathrm{MHz}$, over a period of 7 minutes, using a pulse repetition rate of $1 \mathrm{~s}$. Chemical shifts were referenced to orthophosphoric acid at $0 \mathrm{ppm}$.

Bitumen penetration (Pen, expressed in $\mathrm{dmm}$ ) at $25^{\circ} \mathrm{C}$ and the ring and ball softening point (SP, in ${ }^{\circ} \mathrm{C}$ ) were measured by standard methods [19]. The penetration index (PI) was calculated by [36]

$$
\mathrm{PI}=\frac{12.04\left(\mathrm{SP}-T_{P}\right)-300(2.903-\log (\mathrm{Pen}))}{0.602\left(\mathrm{SP}-T_{P}\right)+30(2.903-\log (\text { Pen }))},
$$

where $T_{P}\left({ }^{\circ} \mathrm{C}\right)$ is the temperature used to measure Pen. 
TABLE 2: SARA analysis of the individual components of bitumen blends.

\begin{tabular}{lcccc}
\hline Component & Saturates & $\begin{array}{c}\text { Aromatics } \\
\text { (wt.\%) }\end{array}$ & $\begin{array}{c}\text { Resins } \\
\text { Asphaltenes }\end{array}$ \\
\hline $\begin{array}{l}\text { Asphaltic } \\
\text { residue (AR) }\end{array}$ & - & $61.6 \pm 1.3$ & $21.7 \pm 1.5$ & $16.7 \pm 1.0$ \\
Vacuum residue & $5.5 \pm 0.7$ & $63.8 \pm 1.7$ & $17.3 \pm 1.5$ & $13.4 \pm 0.9$ \\
(VR) & $4.1 \pm 0.5$ & $92.6 \pm 0.9$ & $3.3 \pm 0.6$ & - \\
SN1 extract & $3.6 \pm 0.3$ & $92.8 \pm 0.6$ & $3.6 \pm 0.5$ & - \\
SN2 extract & $9.9 \pm 0.8$ & $84.9 \pm 1.2$ & $5.2 \pm 0.8$ & - \\
SN3 extract & & & & \\
\hline
\end{tabular}

\section{Results and Discussion}

4.1. SARA and Elemental Analysis of Bitumen Components and Blends. The SARA fractions of the individual bitumen components and of the seven bitumen blends before and after PPA modification are presented in Tables 2 and 3, respectively. Table 3 also presents the elemental analysis of bitumen before PPA modification.

The binary blends (Bit1, Bit2, and Bit3) prepared with asphaltic residue (AR) and one of the extracts (SN1, SN2, or SN3) present similar contents of asphaltenes and resins (within experimental error). In contrast, the concentration of saturates and aromatics differs for the blends prepared with extracts SN1 and SN2 (i.e., Bit1 and Bit2, resp.) and with SN3 extract (i.e., Bit3). For the former, saturates were not detected and the aromatic content is naturally higher (ca. $71 \mathrm{wt}$ \% versus $65.5 \mathrm{wt}$.\% for Bit3) due to the nature of the extracts (see Table 2). However, the differences in elemental composition of the three bitumen blends are negligible (see Table 3).

It is noteworthy that the SARA fractions for binary blend Bit3 (78.39 wt.\% AR + 21.61 wt.\% SN3 extract) are similar to those for Bit7, a binary blend prepared with asphaltic and vacuum residues (30 and $70 \mathrm{wt} . \%$, resp.; see Table 1 ). The most significant difference is the high content of saturates (3.0 wt.\%, Table 3) in Bit7 which can be related to its higher content of vacuum residue (VR). In fact, VR contains $5.5 \mathrm{wt}$.\% of saturates whereas AR, the main component of the other blends, contains no saturates (see Table 2). Again, there are no significant differences for the elemental chemical composition of Bit7 in comparison to the other bitumen samples.

The results for the ternary blends (Bit4-Bit6) prepared with AR, VR, and one of the extracts are quite similar (within experimental error) in what concerns the SARA fractions and elemental composition (Table 3). Overall, these results are consistent with the origin of the blends as they were all prepared with components derived from Arabian light crude oil.

It is worth noting that the elemental analysis of formulated bitumen after PPA addition is not reported in Table 3, as the results were statistically equivalent. In fact, from the literature review, it became clear that PPA modification follows different mechanisms, like redox reactions and disruption of

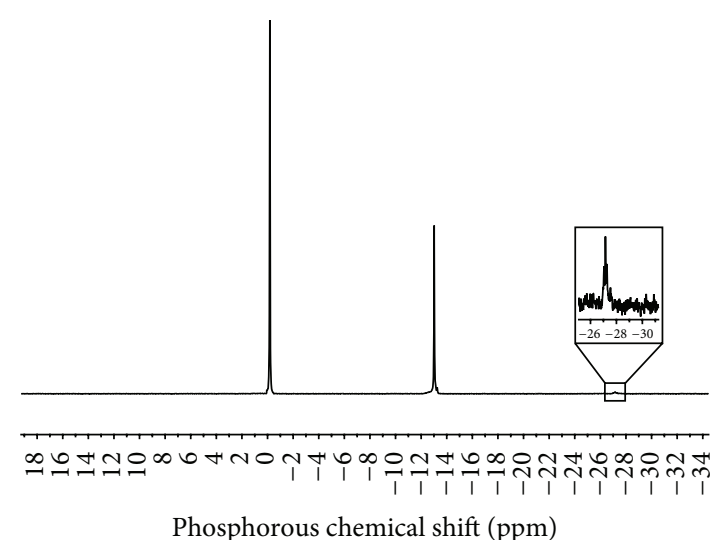

FIGURE 2: ${ }^{31}$ P NMR spectrum of the PPA (105\% grade) used for bitumen modification.

hydrogen bond networks, and none of these mechanisms are expected to change the overall elemental composition of PPAmodified bitumen.

A final comment concerning the absence of saturates in Bitl and Bit2 is in order. In fact, these blends were prepared with extracts SN1 and SN2 which contain ca. 4 wt.\% of saturates (Table 2) and thus the absence of saturates is puzzling. A possible explanation is that the content of saturates is below the TLC-FID apparatus detection limit (detection limit 0.8\%).

The influence of PPA on bitumen composition (SARA fractions) can be visualized in Table 3. In general, PPA modification decreases the content of saturates and resins and increases the fraction of asphaltenes in agreement with the literature $[13,37]$. The higher content of asphaltenes in PPAmodified bitumen explains the experimental results (Table 4), namely, higher softening points (ca. $1-3^{\circ} \mathrm{C}$ increment), lower penetration values (ca. $10 \mathrm{dmm}$ ), and, consequently, an improvement of the penetration index (PI) in accordance with the results reported by Oyekunle [38]. The higher values of PI indicate a change in the colloidal structure of PPAmodified bitumen blends which is expected to improve their thermal susceptibility [13].

The effect of PPA on bitumen modification has been associated with redox reactions involving polycondensed aromatic structures that act as reducing agents for phosphoric acid oligomers $\left(\mathrm{HPO}_{3}\right)_{n}$, which are therefore oxidized [13]. As a result, one would expect the conversion of part of the resins fraction into asphaltenes and the conversion of the saturates and aromatics fractions into resins [13]. However, the increase of the aromatics fraction observed in this work, after PPA addition, suggests that part of the resins were converted to asphaltenes and part were converted to aromatics.

4.2. Analysis of PPA and Modified Bitumen by ${ }^{31} P \mathrm{NMR}$ Spectroscopy. The ${ }^{31} \mathrm{P}$ NMR spectrum of the PPA used in this work is presented in Figure 2. According to the literature $[37,39]$, the resonance peak at $0 \mathrm{ppm}$ is attributed to phosphorus in $\mathrm{H}_{3} \mathrm{PO}_{4}$, a smaller peak at -13 ppm is assigned to phosphorus in end groups of PPA chains, and a much 


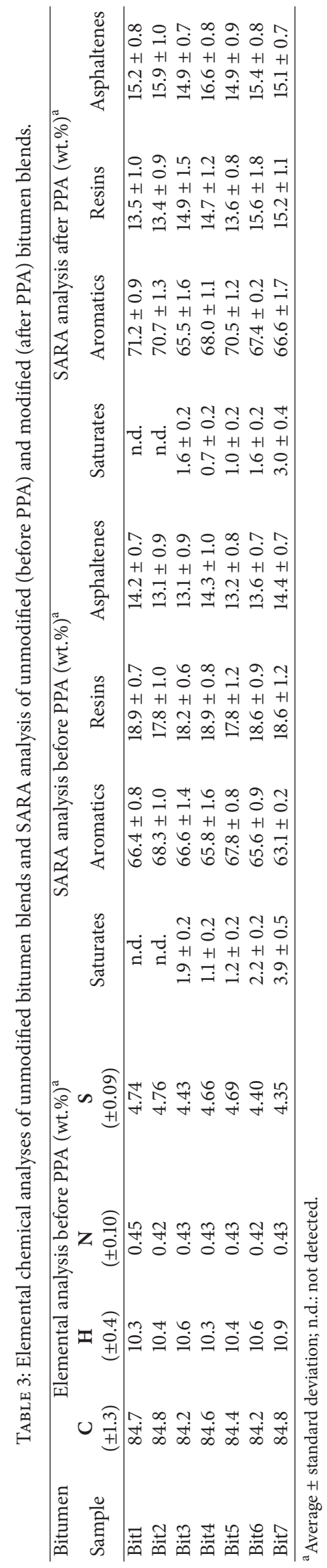


TABLE 4: Characteristic properties of bitumen blends, before and after PPA modification.

\begin{tabular}{|c|c|c|c|c|c|c|}
\hline \multirow{2}{*}{ Blend } & \multicolumn{3}{|c|}{ Before PPA } & \multicolumn{3}{|c|}{ After PPA } \\
\hline & Pen $(\mathrm{dmm})$ & $\mathrm{SP}\left({ }^{\circ} \mathrm{C}\right)$ & PI $(-)$ & Pen $(\mathrm{dmm})$ & $\mathrm{SP}\left({ }^{\circ} \mathrm{C}\right)$ & PI $(-)$ \\
\hline Bitl & 101 & 43.0 & -1.4 & 90 & 43.8 & -1.5 \\
\hline Bit2 & 99 & 43.0 & -1.5 & 88 & 44.0 & -1.5 \\
\hline Bit3 & 103 & 43.0 & -1.4 & 90 & 45.2 & -1.1 \\
\hline Bit4 & 108 & 42.0 & -1.6 & 88 & 44.2 & -1.4 \\
\hline Bit5 & 99 & 43.0 & -1.5 & 95 & 43.8 & -1.3 \\
\hline Bit6 & 110 & 42.2 & -1.5 & 86 & 45.5 & -1.1 \\
\hline Bit7 & 100 & 43.5 & -1.3 & 91 & 45.6 & -0.9 \\
\hline
\end{tabular}

Pen: penetration at $25^{\circ} \mathrm{C}$; SP: ring and ball softening point; PI: penetration index.

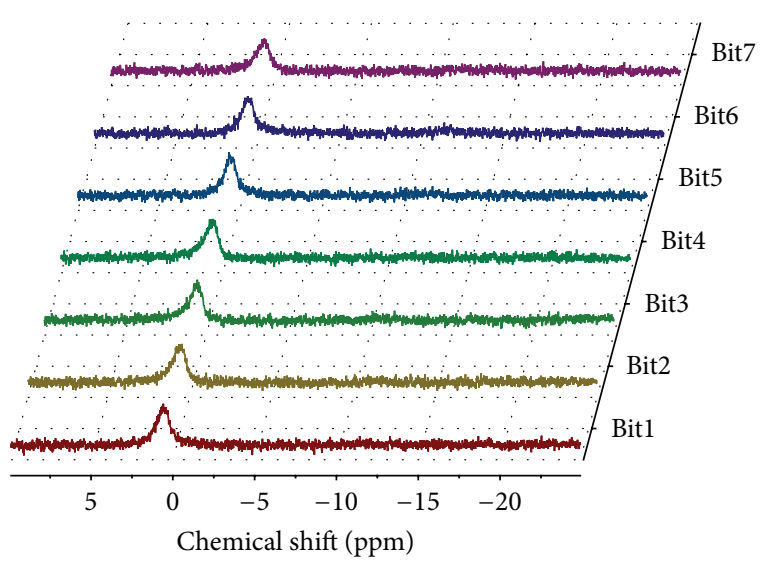

FIgURE $3:{ }^{31} \mathrm{P}$ NMR spectra for PPA-modified bitumen (Bitl-Bit7).

smaller peak around $-26 \mathrm{ppm}$ is attributed to phosphorus in the middle groups of PPA chains.

The PPA-modified bitumen blends were also analyzed by ${ }^{31} \mathrm{P}$ NMR spectroscopy, at room temperature. The spectra for the seven blends (see Figure 3) are very similar revealing a broad signal approximately at $1 \mathrm{ppm}$. This resonance peak, located in the vicinity of the phosphorous resonance peak in $\mathrm{H}_{3} \mathrm{PO}_{4}$, was assigned to hydrophobic interactions between phosphorous and polycondensed aromatic structures typically present in asphaltenes [23]. The absence of resonance peaks assigned to phosphorus in phosphate chains (end and middle groups) suggests that phosphoric esters were not formed during bitumen modification with PPA, in agreement with the results of Miknis and Thomas [39] and in opposition to the earlier hypothesis of Orange et al. [40]. Furthermore, these results indicate that PPA is hydrolyzed completely back to $\mathrm{H}_{3} \mathrm{PO}_{4}$, probably due to the presence of residual water in bitumen [39].

The broader spectral peaks for PPA-modified bitumen blends (Figure 3), in comparison with PPA (Figure 2), are probably due to higher viscosity of the PPA bitumen blends or to the formation of charge transfer complexes between phosphorous and the asphaltene polycondensed aromatic structures [39, 41]. Another hypothesis is that small amounts of paramagnetic impurities typically present in bitumen (e.g., vanadium and nickel) may decrease the relaxation time and, consequently, increase peak broadening due to the Heisenberg uncertainty principle [42].

4.3. Analysis of Unmodified and PPA-Modified Bitumen by ${ }^{1} H$ NMR Spectroscopy. The ${ }^{1} \mathrm{H}$ NMR results for unmodified and PPA-modified bitumen blends are presented in Table 5. The spectra were divided into 12 unequal segments corresponding to well-defined chemical shifts associated with specific groups (i.e., hydrogen types), though minor overlapping may occur [23]. Peak integration in the selected segments generated, after normalization, the relative content of the various proton types (Table 5). The mean values were obtained by averaging the results from the spectra of three aliquots of the same bitumen formulation.

Some conclusions may be drawn from the ${ }^{1} \mathrm{H}$ NMR results (Table 5) more explicitly presented in Figure 4. In general, the content of aliphatic hydrogen (segments 1 and 2, Table 5) in PPA-modified bitumen is different from that in the parent unmodified bitumen. The signals in the segments associated with the branching $(0.5-1.0 \mathrm{ppm})$ and the length (1.0-1.7 ppm) of paraffinic chains are systematically higher, though rather similar. The signals in segment 3 (1.7-1.9 ppm), that is, in the region of chemical shifts associated with sulfur adjacent hydrogen atoms (1.8-3.0 ppm) [27], decrease after PPA modification, thus suggesting more substituted aromatic structures.

The slightly lower signals in segment $6(2.4-3.5 \mathrm{ppm})$, Figure 4, which are associated with the chemical shifts of $\alpha$-hydrogen $\left(\alpha-\mathrm{CH}, \alpha-\mathrm{CH}_{2}\right)$ indicate the occurrence of oxidation reactions, thus explaining the improved stability of PPA-modified bitumen [27]. The signals associated with bridging hydrogen atoms (segment 7, 3.5-4.5 ppm) and hydrogen atoms in monoaromatic structures (segment 9, 6.0-7.2 ppm) have both a tendency to decrease 


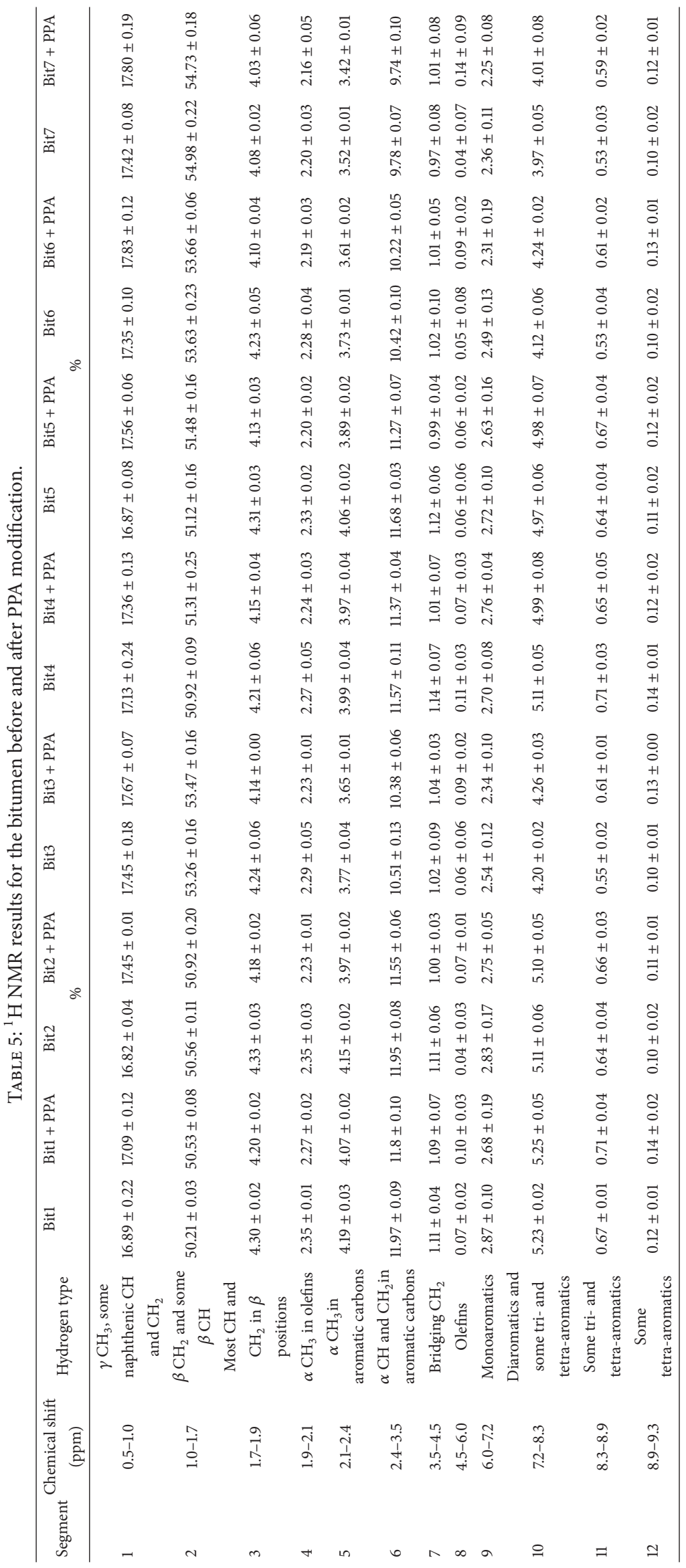




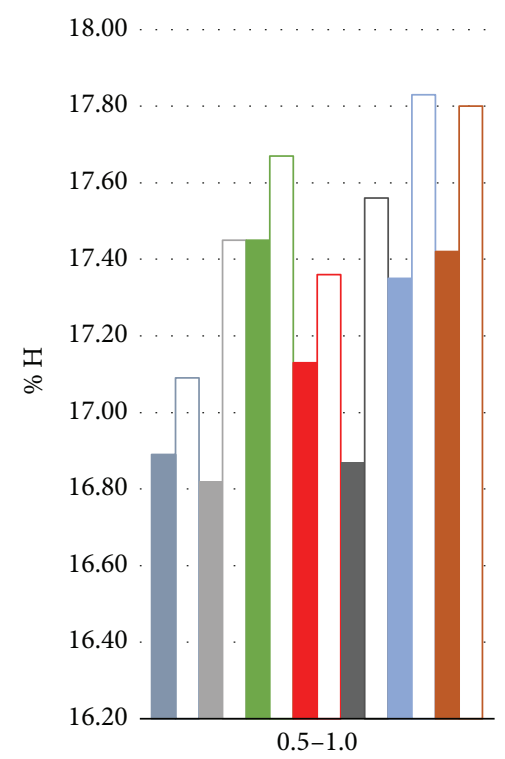

Chemical shift (ppm)

$$
14.00
$$

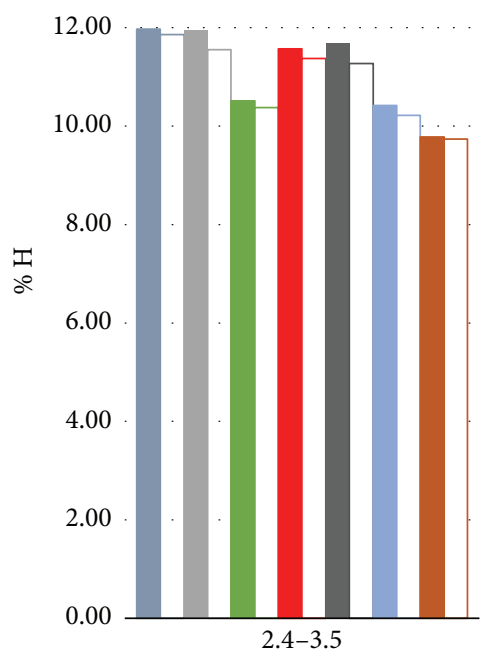

Chemical shift (ppm)

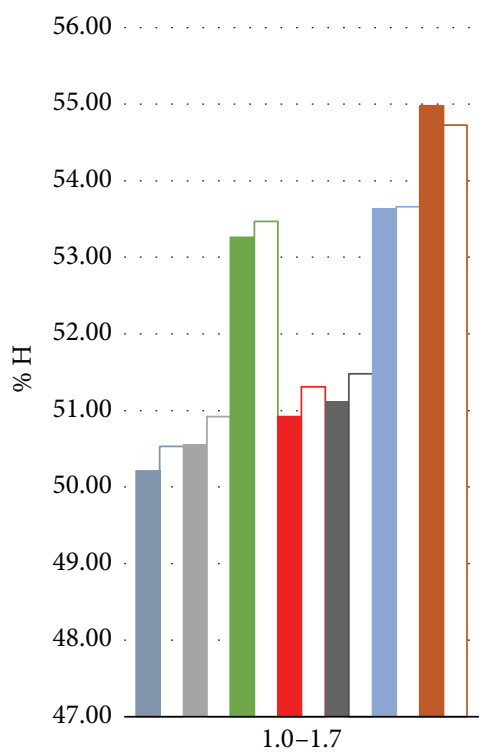

Chemical shift (ppm)

1.20

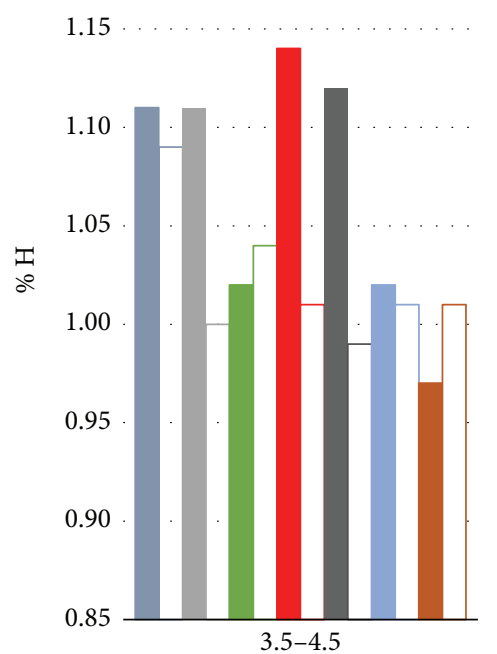

Chemical shift (ppm)

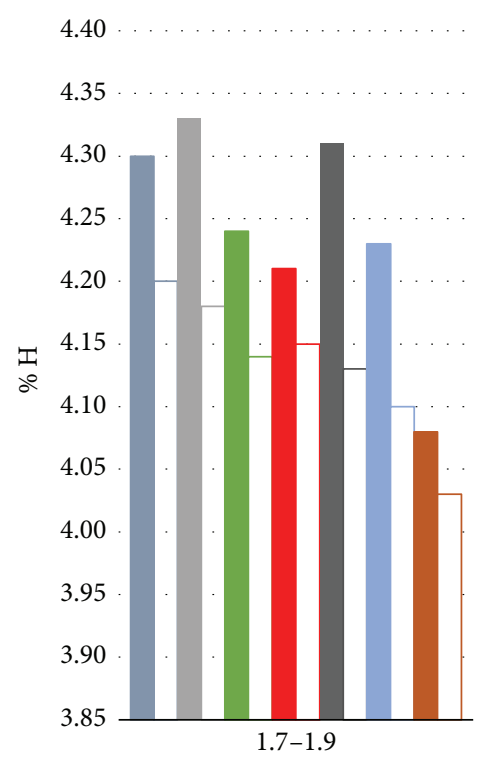

Chemical shift (ppm)
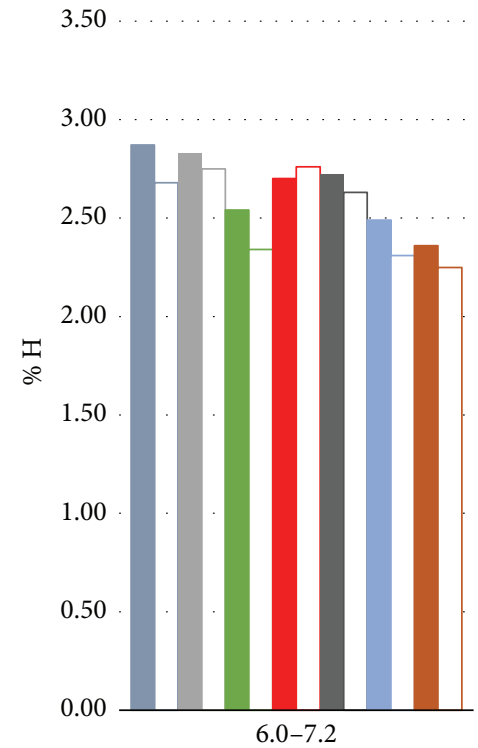

Chemical shift (ppm)

$$
\begin{array}{ll}
\square \text { Bit1 } & \square \text { Bit1 + PPA } \\
\square \text { Bit2 } & \square \text { Bit2 + PPA } \\
\square \text { Bit3 } & \square \text { Bit3 + PPA } \\
\square \text { Bit4 } & \square \text { Bit4 + PPA } \\
\square \text { Bit5 } & \square \text { Bit5 + PPA } \\
\text { Bit6 } & \square \text { Bit6 + PPA } \\
\square \text { Bit7 } & \square \text { Bit7 + PPA }
\end{array}
$$

FIGURE 4: Most significant results from the ${ }^{1} \mathrm{H}$ NMR spectra of bitumen blends before and after PPA addition. The types of hydrogen associated with the chemical shift regions are listed in Table 5.

after PPA modification (see Figure 4). This might be related to a slight increase in the content of hydrogen atoms associated with polyaromatic structures (segments 10,11 , and 12, in Table 5), suggesting an increase in content of condensed structures as reported in the literature [13].
A final note about the residual presence of olefins, detected in the region 4.5-6.0 ppm (segment 8, Table 5). In fact, since bitumen is allegedly free of olefins, due to the process conditions in the refinery, its presence can be attributed to cracking reactions eventually occurring during NMR sample preparation (recall that 
TABLE 6: Summary of issued patents related to bitumen modification with PPA.

\begin{tabular}{lccc}
\hline Year & Type & Patent number & Licensing Company \\
\hline 1973 & Chemically modified bitumen & US3751278 A & Tosco Lion Inc. \\
2009 & US20090249978A1 & Innophos \\
\hline 1991 & & US5070123 A & Exxon Research \& Engineering \\
1996 & & US5565510 A & Montell North America Inc. \\
1996 & US5519073 A & Shell Oil Company \\
1999 & Polymer-modified bitumen & US5880185 A & Elf Exploration Production \\
2000 & & US6117926 A & Mathy Construction Company \\
2000 & & US6031029 A & Ergon \\
2000 & & US6136898 A & Marathon Ashland Petroleum \\
2002 & & US6414056 A & Exxon Mobil \\
2007 & & US20050284333 & ICL Performance Products \\
2008 & & US7985787 & Innophos \\
\hline 2010 & Reclaimed asphalt pavement & US8906152 & Innophos \\
\hline 2006 & \multirow{2}{*}{ Roofing membranes } & US7678467 B2 & ICL Performance Products \\
2013 & & WO2013116637 A1 & ICL Performance Products \\
\hline 2004 & & WO2004081098 A1 & Eurovia \\
2011 & Crumb rubber modified bitumen & WO 2011047032 A2 & Innophos \\
\hline
\end{tabular}

Search criteria. Keywords: (asphalt or bitumen) and (polyphosphoric acid) in title and abstract in Google Patents and Web of Knowledge databases. Accessed in December 2015.

bitumen reheating was necessary to facilitate sample handling) [54].

\section{Conclusions}

Binary and ternary bitumen blends formulated with asphaltic residue, vacuum residue, and aromatic- extracts derived from refined Arabian crude oil were analyzed before and after modification with polyphosphoric acid (PPA). SARA analysis revealed that, in general, PPA modification increased the fraction of asphaltenes in bitumen and decreased the saturates and resins fractions abundance. These changes improved the performance properties, namely, the penetration index (PI), which indicates higher thermal stability of PPA-modified bitumen blends.

With respect to the mechanism of PPA actuation, the ${ }^{31} \mathrm{P}$ NMR proved that PPA is hydrolyzed back to phosphoric acid and reacts with bitumen, probably in the form of charge transfer complexes with polycondensed aromatic structures. This fact was disclosed from the presence of the single resonance peak assigned to phosphoric acid and the absence of peaks assigned to phosphorus in the end and middle groups of phosphate chains. The PPA disrupts the agglomerates of asphaltene micelles, which promotes the distribution of asphaltenes in the maltene phase, thus increasing the content of the aromatic fraction. Furthermore, part of the resins is converted into the aromatic fraction.

Concerning the ${ }^{1} \mathrm{H}$ NMR studies, results suggest that PPA improves the oxidation stability of the bitumen blends and increases the concentration of condensed structures. The former was evidenced by the content drop of $\alpha$-hydrogen (range 2.4-3.5 ppm) after PPA modification, as these hydrogen atoms are associated with oxidation susceptibility.

\section{Appendix}

This appendix presents a literature review concerning bitumen modification with polyphosphoric acid (PPA). Table 6 lists the patents issued since 1973 when Alexander [55] patented a process using PPA to improve bitumen viscosity. Table 7 summarizes the scientific studies performed to evaluate the effect of PPA on bitumen, or bitumen model compounds, and the main characteristics of the ensuing PPAmodified bitumen.

\section{Competing Interests}

The authors declare that there are no competing interests regarding the publication of this paper.

\section{Acknowledgments}

This work was developed within the scope of the projects CICECO-Aveiro Institute of Materials (Ref. FCT UID/CTM/ 50011/2013) and UI QOPNA (Ref. FCT UID/QUI/00062/ 2013), financed by national funds through the FCT/MEC and when appropriate cofinanced by FEDER under the PT2020 Partnership Agreement and the Portuguese National NMR Network (RNRMN). Catarina Varanda also thanks the FCT for a doctoral grant (SFRH/BDE/51420/2011). 


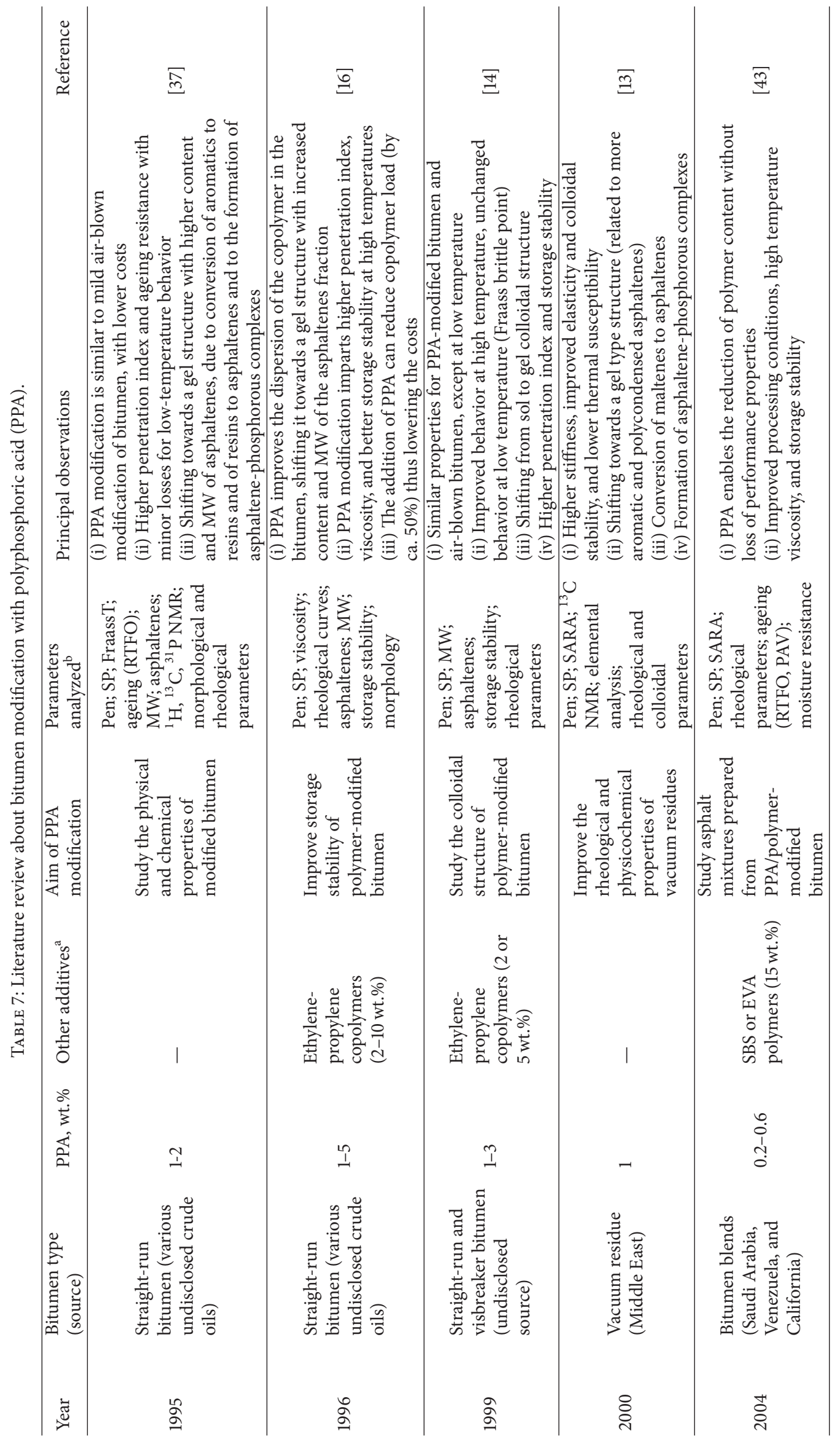




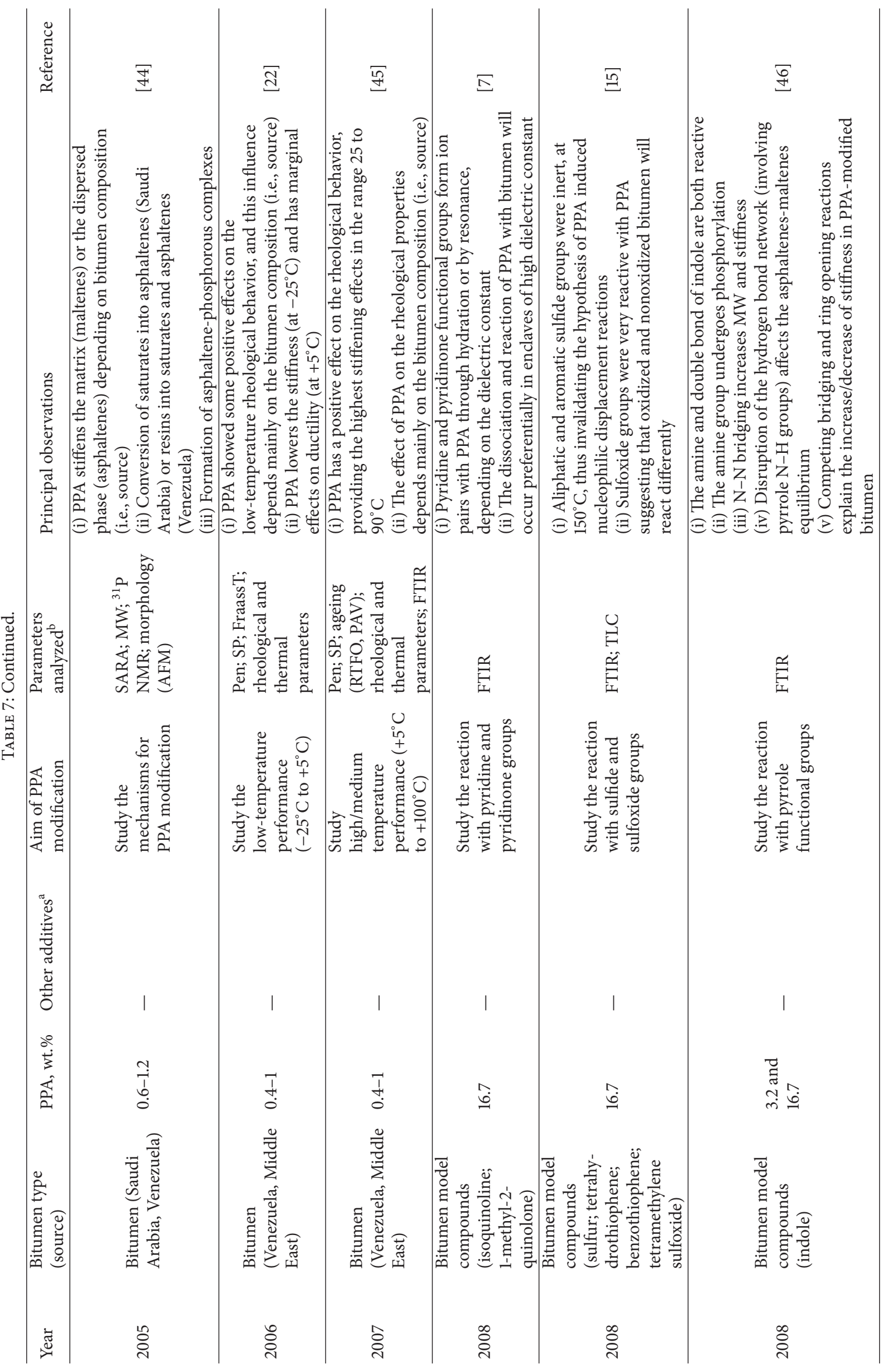




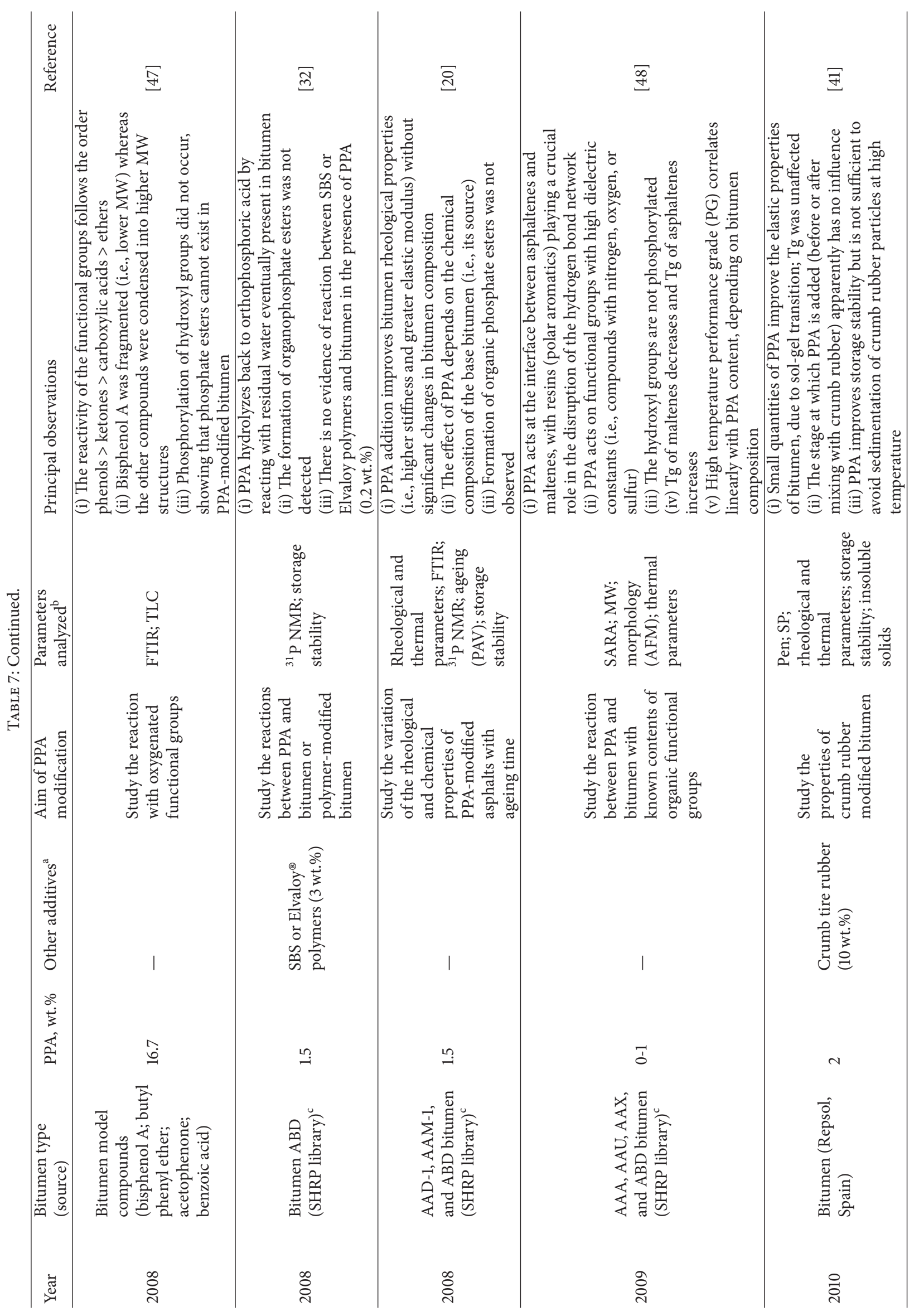




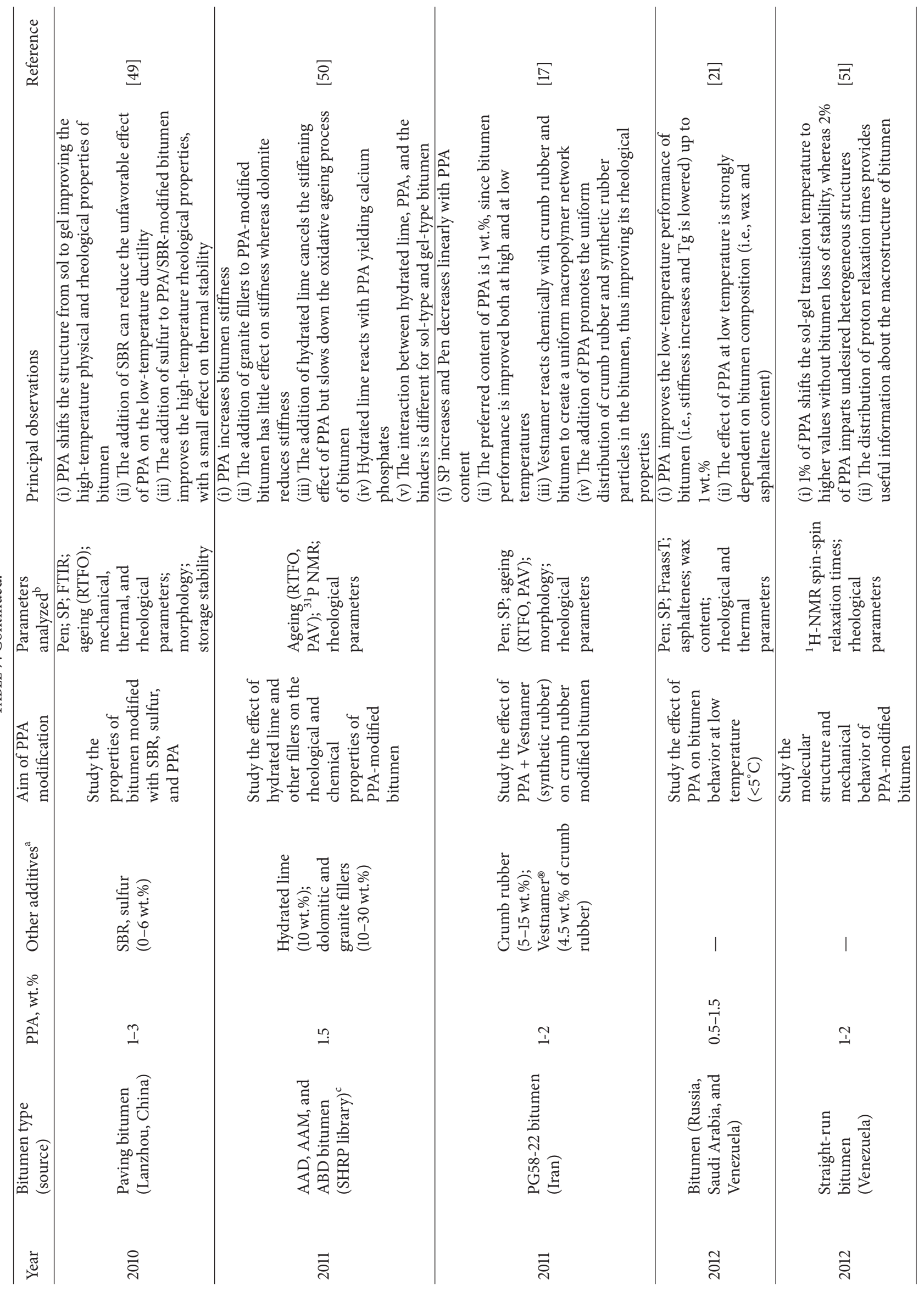




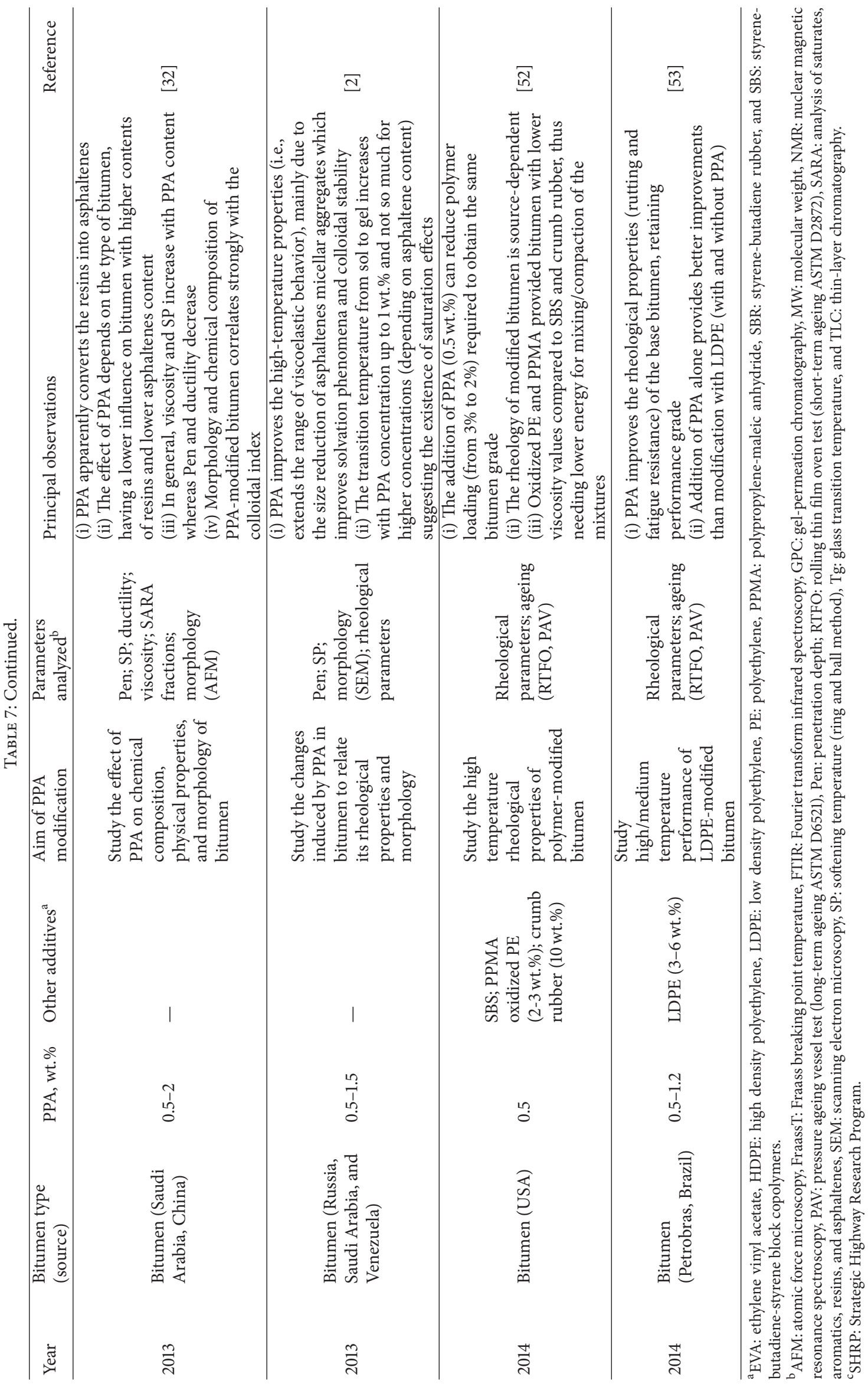




\section{References}

[1] EN 12597: Bitumen and Bituminous Binders-Terminology, European Committee for Standardization, Brussels, Belgium, 2000.

[2] N. Baldino, D. Gabriele, F. R. Lupi, C. Oliviero Rossi, P. Caputo, and T. Falvo, "Rheological effects on bitumen of polyphosphoric acid (PPA) addition," Construction and Building Materials, vol. 40, pp. 397-404, 2013.

[3] J.-F. Masson, "Brief review of the chemistry of polyphosphoric acid (PPA) and bitumen," Energy and Fuels, vol. 22, no. 4, pp. 2637-2640, 2008.

[4] D. R. Jones, “SHRP asphalt research program," Technical Memorandum \#4, Center for Transportation Research, University of Texas, Austin, Tex, USA, 1992.

[5] A. M. Kharrat, J. Zacharia, V. J. Cherian, and A. Anyatonwu, "Issues with comparing SARA methodologies," Energy \& Fuels, vol. 21, no. 6, pp. 3618-3621, 2007.

[6] D. Lesueur, “The colloidal structure of bitumen: consequences on the rheology and on the mechanisms of bitumen modification," Advances in Colloid and Interface Science, vol. 145, no. 1-2, pp. 42-82, 2009.

[7] J.-F. Masson and M. Gagné, "Ionic pairs in polyphosphoric acid (PPA)-modified bitumen: insights from model compounds," Energy \& Fuels, vol. 22, no. 5, pp. 3390-3394, 2008.

[8] A. Rosinger, "Beiträge zur Kolloidchemie des Asphalts," KolloidZeitschrift, vol. 15, no. 5, pp. 177-179, 1914.

[9] F. J. Nellensteyn, "The constitution of asphalt," Journal of the Institution of Petroleum Technologists, vol. 10, pp. 311-323, 1924.

[10] J. P. Pfeiffer and R. N. J. Saal, "Asphaltic bitumen as colloid system," The Journal of Physical Chemistry, vol. 44, no. 2, pp. 139-149, 1940.

[11] C. Y. Cheung and D. Cebon, "Deformation mechanisms of pure bitumen," Journal of Materials in Civil Engineering, vol. 9, no. 3, pp. 117-129, 1997.

[12] B. Brûlé, G. Ramond, and C. Such, "Relationships between composition, structure, and properties of road asphalts: state of research at the French Public Works Central Laboratory," in Proceedings of the 65th Annual Meeting of the Transportation Research Board, pp. 22-34, Transportation Research Board, Washington, DC, USA, 1986.

[13] C. Giavarini, D. Mastrofini, M. Scarsella, L. Barré, and D. Espinat, "Macrostructure and rheological properties of chemically modified residues and bitumens," Energy \& Fuels, vol. 14, no. 2, pp. 495-502, 2000.

[14] F. Bonemazzi and C. Giavarini, "Shifting the bitumen structure from sol to gel," Journal of Petroleum Science and Engineering, vol. 22, no. 1-3, pp. 17-24, 1999.

[15] J.-F. Masson and P. Collins, "FTIR study of the reaction of polyphosphoric acid and model bitumen sulfur compounds," Energy and Fuels, vol. 23, no. 1, pp. 440-442, 2009.

[16] C. Giavarini, P. De Filippis, M. L. Santarelli, and M. Scarsella, "Production of stable polypropylene-modified bitumens," Fuel, vol. 75, no. 6, pp. 681-686, 1996.

[17] G. Yadollahi and H. Sabbagh Mollahosseini, "Improving the performance of Crumb Rubber bitumen by means of Poly Phosphoric Acid (PPA) and Vestenamer additives," Construction and Building Materials, vol. 25, no. 7, pp. 3108-3116, 2011.

[18] G. L. Baumgardner, "Why and how of polyphosphoric acid modification: an industry perspective," in Proceedings of the Workshop on Polyphosphoric Acid Modification of Asphalt Binders, Minneapolis, Minn, USA, 2009.
[19] ASTM, "Standard test method for penetration of bituminous materials," ASTM Standard D5-05, ASTM International, West Conshohocken, Pa, USA, 2005.

[20] S.-C. Huang, T. F. Turner, F. P. Miknis, and K. P. Thomas, "Longterm aging characteristics of polyphosphoric acid-modified asphalts," Transportation Research Record, vol. 2051, pp. 1-7, 2008.

[21] N. Baldino, D. Gabriele, C. O. Rossi, L. Seta, F. R. Lupi, and P. Caputo, "Low temperature rheology of polyphosphoric acid (PPA) added bitumen," Construction and Building Materials, vol. 36, pp. 592-596, 2012.

[22] Y. Edwards, Y. Tasdemir, and U. Isacsson, "Rheological effects of commercial waxes and polyphosphoric acid in bitumen 160/220-low temperature performance," Fuel, vol. 85, no. 7-8, pp. 989-997, 2006.

[23] V. D. Molina, U. N. Uribe, and J. Murgich, "Correlations between SARA fractions and physicochemical properties with $1 \mathrm{H}$ NMR spectra of vacuum residues from Colombian crude oils," Fuel, vol. 89, no. 1, pp. 185-192, 2010.

[24] C. Obiosa-Maife and J. M. Shaw, "Toward identification of molecules in ill-defined hydrocarbons using infrared, raman, and nuclear magnetic resonance (NMR) spectroscopy," Energy \& Fuels, vol. 25, no. 2, pp. 460-471, 2011.

[25] E. M. Dickinson, "Average structures of petroleum pitch fractions by $1 \mathrm{H} 13 \mathrm{C}$ n.m.r. spectroscopy," Fuel, vol. 64, no. 5, pp. 704-706, 1985.

[26] E. M. Dickinson, "Structural comparison of petroleum fractions using proton and 13C n.m.r. spectroscopy," Fuel, vol. 59, no. 5, pp. 290-294, 1980.

[27] P. W. Jennings, J. A. Pribanic, M. A. Desando et al., "Binder characterization and evaluation by nuclear magnetic resonance spectroscopy," SHRP Report A-335, National Research Council, Washington, DC, USA, 1993.

[28] L. Michon, D. Martin, J.-P. Planche, and B. Hanquet, "Estimation of average structural parameters of bitumens by $13 \mathrm{C}$ nuclear magnetic resonance spectroscopy," Fuel, vol. 76, no. 1, pp. 9-15, 1997.

[29] L. Michon, D. A. Netzel, B. Hanquet, D. Martin, and J.-P. Planche, "Carbon-13 molecular structure parameters of RTFOT aged asphalts: three proposed mechanisms for aromatization," Petroleum Science and Technology, vol. 17, no. 3-4, pp. 369-381, 1999.

[30] M. N. Siddiqui and M. F. Ali, "Investigation of chemical transformations by NMR and GPC during the laboratory aging of Arabian asphalt," Fuel, vol. 78, no. 12, pp. 1407-1416, 1999.

[31] M. N. Siddiqui, "NMR fingerprinting of chemical changes in asphalt fractions on oxidation," Petroleum Science and Technology, vol. 28, no. 4, pp. 401-411, 2010.

[32] L. Gentile, L. Filippelli, C. O. Rossi, N. Baldino, and G. A. Ranieri, "Rheological and ${ }^{1} \mathrm{H}-\mathrm{NMR}$ spin-spin relaxation time for the evaluation of the effects of PPA addition on bitumen," Molecular Crystals and Liquid Crystals, vol. 558, pp. 54-63, 2012.

[33] C. Jiang, S. R. Larter, K. J. Noke, and L. R. Snowdon, "TLC-FID (Iatroscan) analysis of heavy oil and tar sand samples," Organic Geochemistry, vol. 39, no. 8, pp. 1210-1214, 2008.

[34] "Standard test methods for instrumental determination of carbon, hydrogen, and nitrogen in petroleum products and lubricants," ASTM D5291-10, ASTM International, West Conshohocken, Pa, USA, 2010.

[35] IP 336: petroleum products-determination of sulfur contentenergy-dispersive-X-ray fluorescence method, Institute of Petroleum Standard Test Methods, 2004. 
[36] J. G. Speight, The Chemistry and Technology of Petroleum, Taylor \& Francis, 5th edition, 2014.

[37] P. De Filippis, C. Giavarini, and M. Scarsella, "Improving the ageing resistance of straight-run bitumens by addition of phosphorus compounds," Fuel, vol. 74, no. 6, pp. 836-841, 1995.

[38] L. O. Oyekunle, "Influence of chemical composition on the physical characteristics of paving asphalts," Petroleum Science and Technology, vol. 25, no. 11, pp. 1401-1414, 2007.

[39] F. P. Miknis and K. P. Thomas, "NMR analysis of polyphosphoric acid-modified bitumens," Road Materials and Pavement Design, vol. 9, no. 1, pp. 59-72, 2008.

[40] G. Orange, D. Depuis, J. V. Martin, F. Farcas, C. Such, and B. Marcant, "Chemical modification of bitumen through PPA: properties-microstructure relationship," in Proceedings of the 3rd Euroasphalt and Eurobitume Consgress, Vienna, Austria, May 2004.

[41] P. De Filippis, C. Giavarini, and M. Scarsella, "Stabilization and partial deasphaltening of thermal residues by chemical treatment," Energy \& Fuels, vol. 8, no. 1, pp. 141-146, 1994.

[42] M. Balci, Basic 1H- and 13C-NMR Spectroscopy, Elsevier Science, Amsterdam, The Netherlands, 1st edition, 2005.

[43] G. Orange, J.-V. Martin, A. Menapace, M. Hemsley, and G. L. Baumgardner, "Rutting and moisture resistance of asphalt mixtures containing polymer and polyphosphoric acid modified bitumen," Road Materials and Pavement Design, vol. 5, no. 3, pp. 323-354, 2004.

[44] G. L. Baumgardner, J. F. Masson, J. R. Hardee, A. M. Menapace, and A. G. Williams, "Polyphosphoric acid modified asphalt: proposed mechanisms," Journal of the Association of Asphalt Paving Technologists: From the Proceedings of the Technical Sessions, vol. 74, pp. 283-305, 2005.

[45] Y. Edwards, Y. Tasdemir, and U. Isacsson, "Rheological effects of commercial waxes and polyphosphoric acid in bitumen 160/220 - high and medium temperature performance," Construction and Building Materials, vol. 21, no. 10, pp. 1899-1908, 2007.

[46] J.-F. Masson and M. Gagné, "Polyphosphoric acid (PPA)modified bitumen: disruption of the asphaltenes network based on the reaction of nonbasic nitrogen with PPA," Energy and Fuels, vol. 22, no. 5, pp. 3402-3406, 2008.

[47] J.-F. Masson, M. Gagné, G. Robertson, and P. Collins, "Reactions of polyphosphoric acid and bitumen model compounds with oxygenated functional groups: where is the phosphorylation?" Energy \& Fuels, vol. 22, no. 6, pp. 4151-4157, 2008.

[48] F. Zhang and J. Yu, "The research for high-performance SBR compound modified asphalt," Construction and Building Materials, vol. 24, no. 3, pp. 410-418, 2010.

[49] V. González, F. J. Martínez-Boza, F. J. Navarro, C. Gallegos, A. Pérez-Lepe, and A. Páez, "Thermomechanical properties of bitumen modified with crumb tire rubber and polymeric additives," Fuel Processing Technology, vol. 91, no. 9, pp. 10331039, 2010.

[50] J. F. Masson, P. Collins, J. R. Woods, S. Bundalo-Perc, and J. Margeson, "Chemistry and effects of polyphosphoric acid on the microstructure, molecular mass, glass transition temperatures and performance grades of asphalts," Journal of the Association of Asphalt Paving Technologists, vol. 78, pp. 455-490, 2009.

[51] S.-C. Huang, F. P. Miknis, W. Schuster, S. Salmans, M. Farrar, and R. Boysen, "Rheological and chemical properties of hydrated lime and polyphosphoric acid-modified asphalts with long-term aging," Journal of Materials in Civil Engineering, vol. 23, no. 5, pp. 628-637, 2011.

[52] K. Yan, H. Zhang, and H. Xu, "Effect of polyphosphoric acid on physical properties, chemical composition and morphology of bitumen," Construction and Building Materials, vol. 47, pp. 9298, 2013.

[53] F. Xiao, S. Amirkhanian, H. Wang, and P. Hao, "Rheological property investigations for polymer and polyphosphoric acid modified asphalt binders at high temperatures," Construction and Building Materials, vol. 64, pp. 316-323, 2014.

[54] M. R. Gray and W. C. McCaffrey, "Role of chain reactions and olefin formation in cracking, hydroconversion, and coking of petroleum and bitumen fractions," Energy and Fuels, vol. 16, no. 3, pp. 756-766, 2002.

[55] S. Alexander, "Method of treating asphalt," United States Patent 3751278, 1973. 

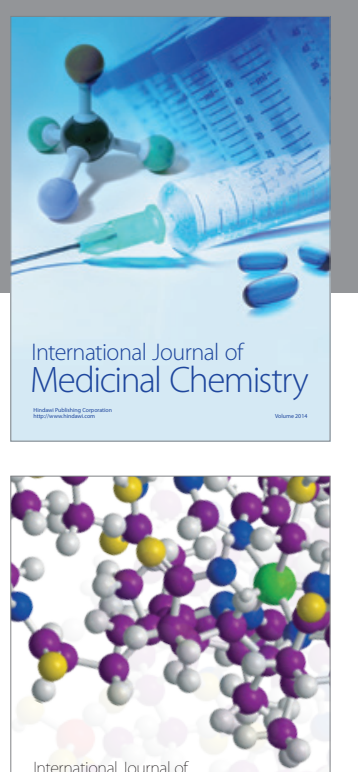

Carbohydrate Chemistry

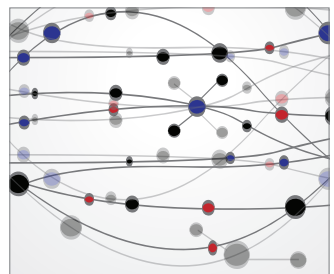

The Scientific World Journal
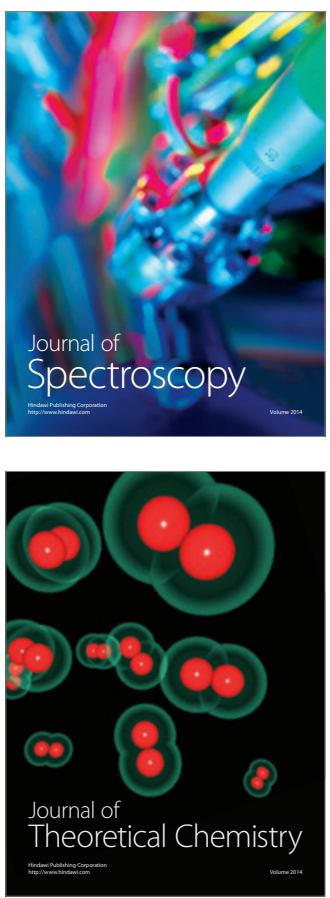
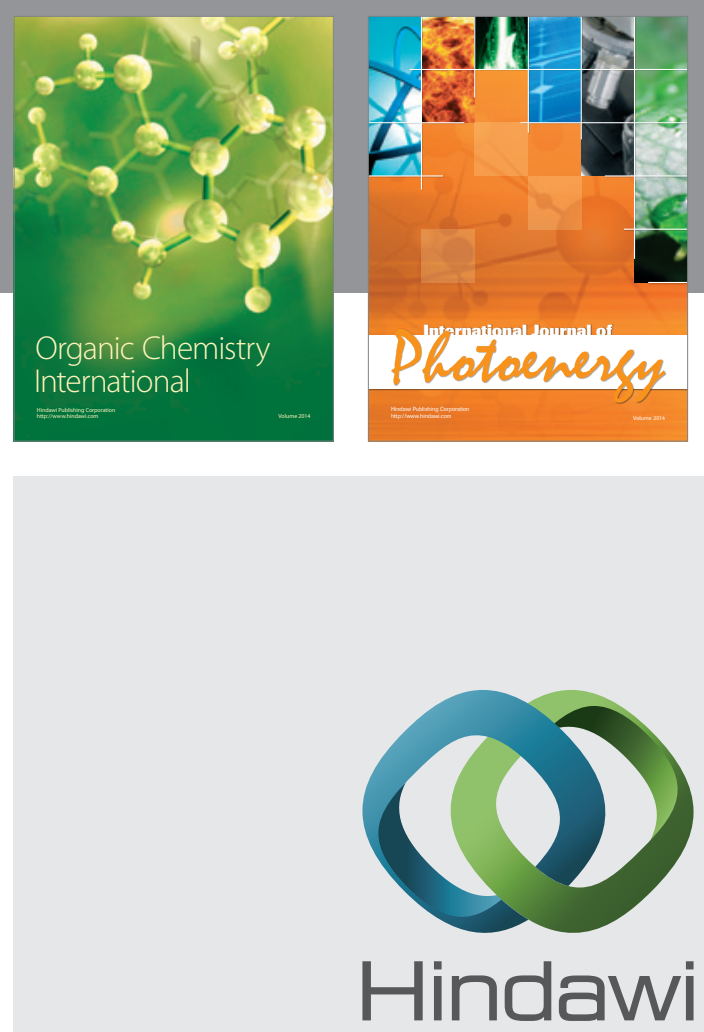

Submit your manuscripts at

http://www.hindawi.com

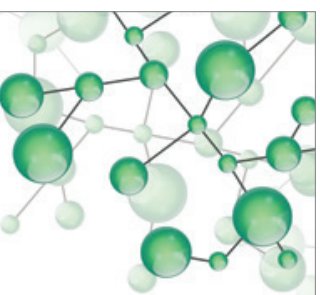

International Journal of

Inorganic Chemistry

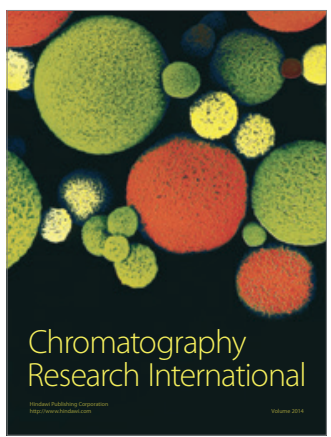

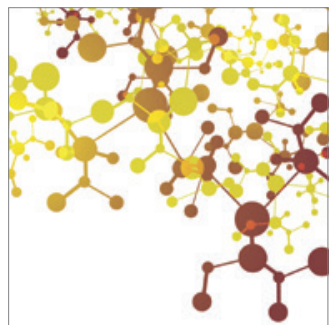

Applied Chemistry
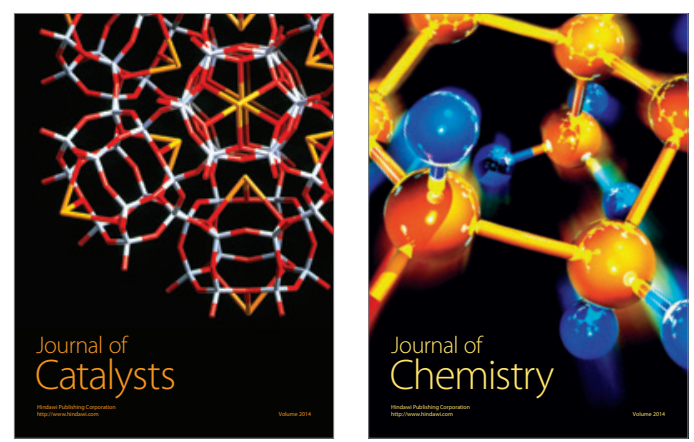
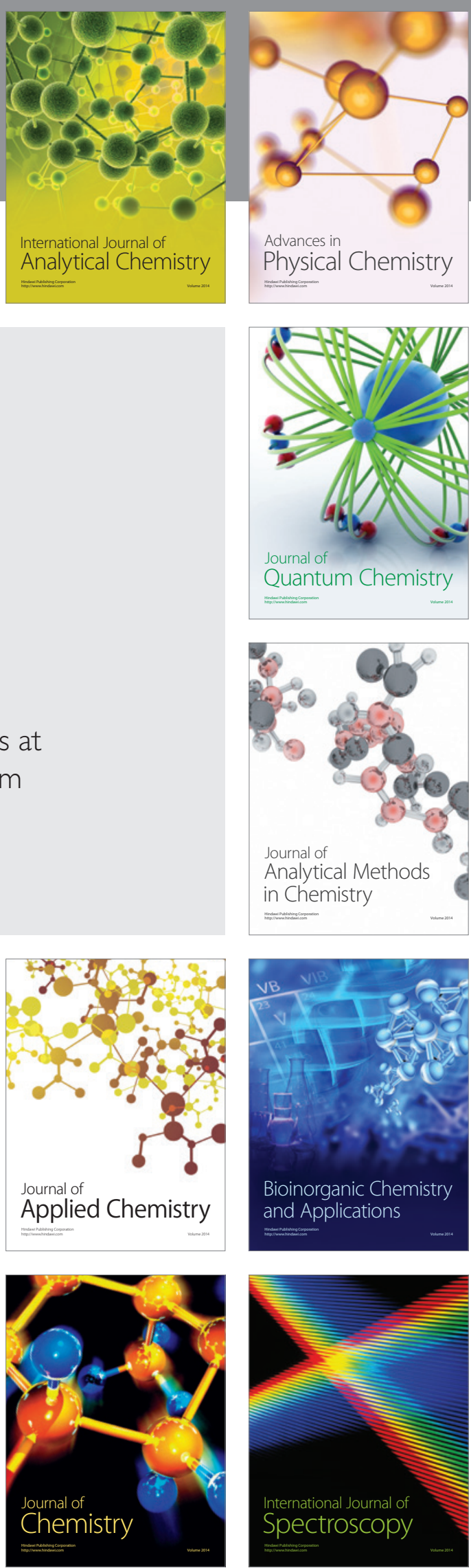